\title{
Identifying the most critical project complexity factors using Delphi method: the Iranian construction industry
}

\author{
Mohammad Mehdi Mozaffari, Safar Fazli and Ali Sedaghat-Seresht*
}

Department of Management, Faculty of social science, Imam Khomeini International University, Qazvin, Iran

\begin{tabular}{|c|c|}
\hline A R T I C L E I N F O & A B S T R A C T \\
\hline $\begin{array}{l}\text { Article history: } \\
\text { Received July 28, } 2012 \\
\text { Received in Revised form } \\
\text { August, 26, } 2012 \\
\text { Accepted } 12 \text { September } 2012 \\
\text { Available online } \\
\text { 16 September } 2012 \\
\text { Keywords: } \\
\text { Project complexity } \\
\text { Delphi method } \\
\text { Construction industry }\end{array}$ & $\begin{array}{l}\text { Complexity is one of the most important issues influencing success of any construction project } \\
\text { and there are literally different studies devoted to detect important factors increasing } \\
\text { complexity of projects. During the past few years, there have been growing interests in } \\
\text { developing mass construction projects in Iran. The proposed study of this paper uses Delphi } \\
\text { technique to find out about important factors as barriers of construction projects in Iran. The } \\
\text { results show that among } 47 \text { project complexity factors, } 19 \text { factors are more important than } \\
\text { others are. The study groups different factors into seven categories including environmental, } \\
\text { organizational, objectives, tasks, stakeholders, technological, information systems and } \\
\text { determines the relative importance of each. In each group, many other sub group activities are } \\
\text { determined and they are carefully investigated. The study provides some detailed suggestions } \\
\text { on each category to reduce the complexity of construction project. }\end{array}$ \\
\hline
\end{tabular}

\section{Introduction}

Complexity is one of the most challenging and controversial issues influencing most complicated systems. Underrating the behavior of systems' complexity normally helps setup appropriate actions to reduce unwanted consequences (Williams, 1999). Thomas and Mengel (2008) explained the increasing interest in project management but argued that still many projects continue to fail at an increasing rate. Complexity, chaos and uncertainty play important role in failure of many projects and project environments is receiving acceptance in both research and practice. Therefore, we need to study project management education and develop project managers to deal with the increasing level of complexity, chaos, and uncertainty in many projects including mass construction projects. Thomas and Mengel (2008) discussed new perspectives and concepts for an advanced level of project management education, which could help develop the capabilities required to look for the dynamic organizational environments and complex projects. They explained the evolution of project * Corresponding author.

E-mail addresses: ali_sedaghat_seresht@yahoo.com (A. Sedaghat-Seresht) 
management and project management education and project management training programs and explained the relative importance on standardization of the field and on preparation for the professional designation of project managers. They also discussed the effect of taking complexity on the necessities for professional development of project managers by looking for the requirements in preparing project managers to deal with complexity and presented a framework for project manager development. They also explained the characteristics of a suitable framework of project management education, which would include uncertainty and unknown possibilities. More specifically, they studied how distance-based education in project management could facilitate a learning community, which collaboratively questions existing theory and practice and developed innovative approaches as well as caters to the requirements of project management practitioners for extensive learning opportunities within a flexible learning environment.

Bosch-Rekveldt et al. (2011), in another survey, presented a model for characterizing project complexity in large engineering projects, which could be implemented to adapt the front-end development phase of engineering projects to the specific complexity. They explained that a big portion of previous studies demonstrated that "complexity" was an important issue in current project management research. However, no generally accepted framework can be found to support the characterizing and understanding of project complexity, which appreciates the richness of project complexity in large engineering projects. Therefore, they used Technical, Organizational, and Environmental (TOE) model based on a literature survey constructing a work and on new empirical work consisting of eighteen interviews about six projects in the process engineering industry. They explained that their framework could be implemented to evaluate the complexity of engineering projects. While there are different types of projects, this study is focused on the complexity of Iranian construction industry and projects.

Iran, as a developing country, invests a big part of her annual income in the construction industry. Thus, this industry has a significant role in Iranian economy by generating employment and wealth. The Iranian construction industry, with an annual turnover of US\$38.4 billion continues to grow with an average growth of 4.40\% over the period of 2008-2012 (Asnaashari et al., 2009a, Asnaashari et al., 2009b). However, the process of construction is slow, inefficient and costly and also is faced with many problems (Asnaashari et al., 2009; Asnaashari et al., 2010). Thus, our purpose in this research is to identify the most important factors in project complexity. In this paper, a review of literature is performed to identify the factors, which have been cited by researchers and then the Delphi method is used to choose the most important factors among them. The organization of this paper first presents literature review in section 2. Section 3 explains details of survey and section 4 is devoted to Delphi explanation. Finally, section 5 gives details of the results of this survey and concluding remarks are given in section 6 to summarize the contribution of the paper.

\section{Literature review}

\subsection{Complexity}

Complexity theory has been used over the past few decades in different areas such as physics, astronomy, finance, biology, geology, chemistry and metrology (Thomas \& Mengel, 2008; Whitty \& Maylor, 2009). Complexity concepts can be understood in various ways and it is used in various fields. Complexity also has various connotations within the same field. Sometimes complexity takes into account as an accurate concept, and sometimes as an ambiguous idea (Morel \& Ramanujam, 1999; Latva-Koivisto, 2001; Vidal et al., 2011a). Edmonds (1999) explained complexity as a property of a language expression, which makes it difficult to formulate its overall behavior even when we have almost complete figures about its atomic components and their interrelations. A complex system is a system, which has several, often conflicting components to satisfy and which place substantial cognitive demands on the task-doer for execution (McComb et al., 2007). The behavior of a complex 
system cannot be simply interpreted from its behavior of its elements (Whitty \& Maylor, 2009). Maguire and McKelvey (1999) proposed a definition of complex systems as follows:

"A complex system is a system (whole) comprised of numerous interacting entities (parts), each of which is behaving in its local context according to some rules, laws and forces. In responding to their own particular local context, these individual parts, can, despite acting in parallel without explicit inter-part coordination or communication, cause the system as a whole to display emergent patterns - orderly phenomena and properties- at the global or collective level "

When researchers are talking about complexity and complex systems, they often utilize two concepts: "complex adaptive systems" and "edge of chaos". Complex adaptive systems are basic units of analysis in complexity science (Uhl-Bien et al., 2007). Complex adaptive systems comprise large number of independent agents, each capable of behaving based on unique principles of interaction and relationships. These systems do not simply respond to events, but evolve or learn. Each agent is guided by its own schema, rules and regulations of behavior and by a scheme shared with other agents. Complex adaptive systems are also spontaneously self-reorganizing (Aram \& Noble, 1999; Axelrod et al., 2001; Thomas \& Mengel, 2008). Complexity arises when complex systems are placed at the mid-point between order and disorder (Maguire \& McKelvey, 1999; Geraldi, 2008). Langton termed this coexistence of ordered and chaotic behavior in systems as the edge of chaos (Geraldi, 2008). According to Waldrop (1992), the edge of chaos is where life has sufficient stability to keep and protect itself and enough creativity to deserve the name of life. It is the constantly shifting battle zone among stagnation and anarchy (Aram \& Noble, 1999). As a conclusion, researchers consider that complex systems have the following characteristics (Edmonds, 1999; Axelrod et al., 2001; Parwani, 2002; Bertelsen, 2004; Vidal et al. 2011a):

- Large number of interacting elements

- Emerging behavior

- Self organization and self modification

- Upward and downward causation (There is a reciprocal relation between system's agents and system as a whole)

- Non-linearity (There is no proportionality between inputs and outputs of the system)

- Unpredictability (We cannot expect the future state of a complex system in any detail)

- Exhibits at the edge of chaos

\subsection{Project complexity}

Projects are considered as complex systems, which need management, not only because they face with technological issues but because a set of large organizational factors surrounds them and it is difficult to control them for project managers (Whitty \& Maylor, 2009). Projects made up of large number of parts such as teams, departments, stakeholders, etc. interact in a non-simple way. In these systems, the whole is more than the sum of the parts and characteristics and interactions among parts make it difficult for the human mind to predict its behavior (Williams, 2002). According to Vidal et al. (2011a), project complexity is a property for every project, which makes it hard to understand and keep everything under control, even when we have enough information about the project system. Most projects can be more readily explained as complex adaptive systems than simple systems can. All projects exhibit the attributes of interconnectedness, hierarchy, communication, control and emergences, attributes, which are generally useful in describing all kinds of systems. Most large and many small projects show the characteristics of complex adaptive systems. They exhibit different characteristics such as phase transition, adaptiveness and sensitivity to initial conditions. These latter characteristics can be explained through reference to Complexity Theory (Remington and Pollack, 2007). According to Hass (2009), some sources of project complexity can be expressed in the form of Table 1 as follows. 


\section{Table 1}

Some sources of project complexity (Hass, 2009)

\begin{tabular}{ll}
\hline Project complexity Sources & Description \\
\hline Details & Number of variables and interfaces \\
Ambiguity & Lack of awareness of events and causality \\
Uncertainty & In ability to pre-evaluate actions \\
Unpredictability & Inability to know what will happen \\
Dynamics & Rapid rate of change \\
Social structure & Numbers and types of interactions \\
\hline
\end{tabular}

Many scientists emphasized the relative importance of complexity to the project management process: Project complexity helps determine planning, coordination and control requirements. It also prevents the clear identification and definition of objectives. It has a major role in the selection of an appropriate project organizational form, selection of project inputs, and selection of a suitable project procurement arrangement; and finally it influences on the project objectives of time, cost and quality (Baccarini, 1996).

\section{Research methodology}

In order to perform this research, first a comprehensive literature on the complexity of projects has been conducted. Then, 47 complexity factors raised in the scope of construction industry have been identified. These factors are utilized as input in Delphi process. In next stage, Delphi method is using in order to identify the weights of each factor. Finally, the most important factors will be selected and they will be classified to be understood better.

\section{Delphi method}

Olaf Helmer, Norman C. Dalkey, and Theodore J. Gordon developed Delphi Process at The Rand Corporation. The Delphi Process is a unique method of eliciting and refining group judgment, based on the rationale that $n$ heads are better than one when exact knowledge is not available (Jolson \& Rossow, 1971). It has proven over the years to be a very popular tool for framework building, forecasting, issues prioritizing, decision-making, etc (Vidal et al., 2011b). Okoli and Pawlowski (2004) cited some applications of the Delphi method in the research process which include:

- Identification of the research topic

- Specification of research question(s)

- Identification of a theoretical perspective for the research

- Selection of variables of interest/generation of propositions

- Preliminary identification of causal relationships

- Definition of constructs and creation of a common language for discourse

Four key features may be regarded as necessary for defining a procedure as a 'Delphi'. These are: anonymity, iteration, controlled feedback, and the statistical aggregation of group response. Anonymity is obtained through the implementation of questionnaires. By allowing the individual group members the opportunity to express their opinions and judgments privately, undue social pressures, as from dominant or dogmatic individuals or from a majority, should be avoided. Ideally, this should allow the individual group members to consider each idea on the basis of merit alone, rather than on the basis of potentially invalid criteria (such as the status of an idea's proponent). Furthermore, with the iteration of the questionnaire over a number of rounds, the individuals are given the opportunity to change their opinions and judgments without fear of losing face in the eyes of the (anonymous) others in the group (Rowe \& Wright, 1999). In order to utilizing the Delphi method, the following steps should be performed (see Fig. 1): 


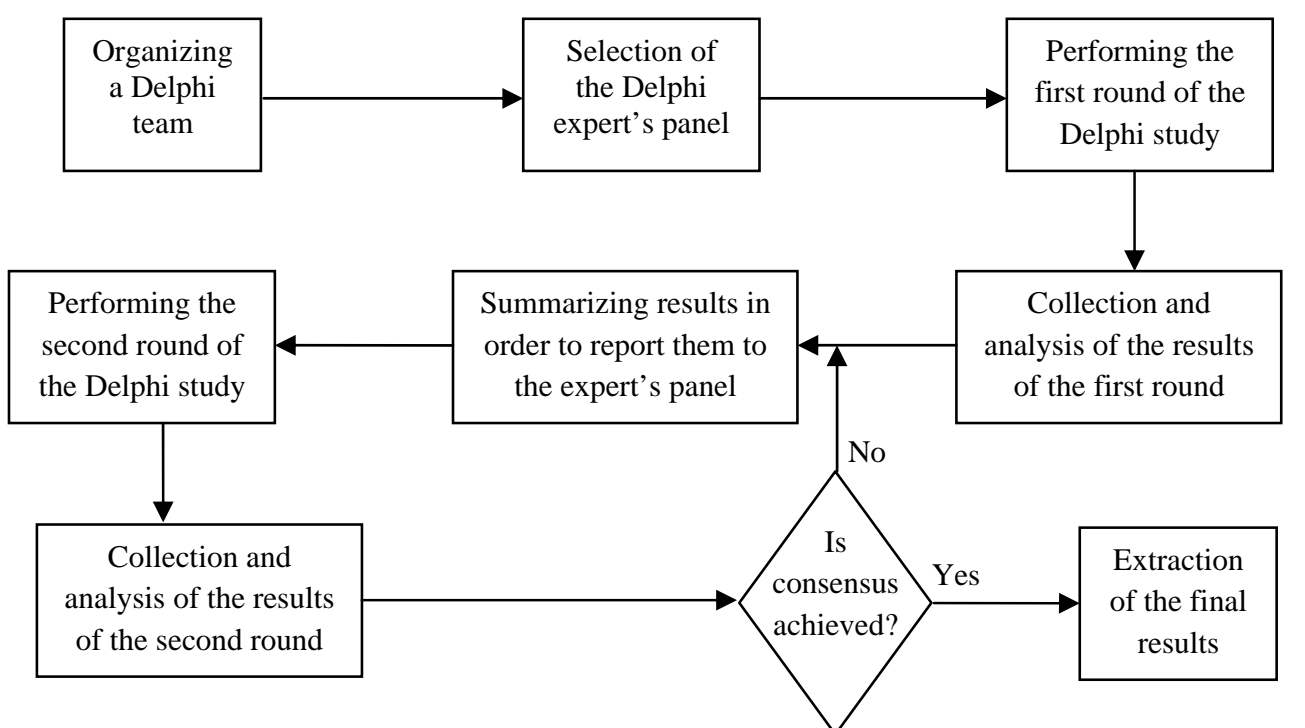

Fig. 1. The Delphi process

1. Organizing a Delphi team

2. Selection of the Delphi experts panel

3. Performing the first round of the Delphi study

4. Collection and analysis of the results of the first round

5. Summarizing results in order to report them to the experts panel
6. performing the second round of the Delphi study

7. Collection and analysis of the results for the $2^{\text {nd }}$ round

8.Checking out the results of two rounds to see if consensus is achieved

9. Extraction of the final results

In the first step the Delphi team should be formed in order to choose experts' panel, prepare questionnaires, gather and analyze the responses and provide feedback, and control and report of the process (Ogot \& Okudan-Kremer, 2004). In the second step, the expert's panel is chosen by Delphi team. The experts should have enough knowledge and experience, willingness and time to take part in the survey, and good communication skills as well (Vidal et al., 2011 b). Based on these features, our team selected 14 experts to perform the Delphi process, 9 of them being industrial practitioners and 5 being academics. Industrial practitioners comprise project managers who work for large firms and organizations. Academics include faculty and university professors who work in the field of project management and have competencies in the project area. The questionnaire started with a short explanation about the research. In the next section, all 47 factors classified into 7 groups were presented to experts with a brief description for each factor. In order to prepare the questions, a 5level Likert scale was utilized to show the importance of factors to project complexity as follows,

\section{Table 2}

5-level Likert scale

\begin{tabular}{llllll}
\hline No. & 1 & 2 & 3 & 4 & 5 \\
\hline Description & Not at all important & slightly important & fairly important & Quite important & Very important \\
\hline
\end{tabular}

Moreover, the respondents were permitted to express their own opinions in the comment section, which was placed in front of each factor and at the bottom of questionnaire. After the questionnaires were filled out by respondents in the first round, the results were collected and analyzed by Delphi team. Then, the results were reported to panelists and the second round was implemented. Comparison of the results of round 1 and 2 revealed that some changes occurred in a series of responses. Similarly, the third round should have been conducted. After performing three rounds, the Delphi team perceived that the consensus has been achieved since there was no further change. So, the final results were obtained and illustrates in Table 3. 


\section{Table 3}

The final results of Delphi method

\begin{tabular}{|c|c|c|c|c|c|}
\hline Factors & Average & Sta. Dev & Factors & Average & Sta. Dev \\
\hline Environmental dependency & 4.29 & 0.73 & Clarity of line of command & 2.93 & 0.62 \\
\hline Cultural Diversity & 3.93 & 0.92 & Number of objectives & 3.21 & 0.58 \\
\hline Project environment stability & 4.29 & 0.73 & Interdependence of objectives & 4.43 & 0.65 \\
\hline Environmental risk & 2.86 & 0.86 & Clarity of objectives & 4.21 & 0.89 \\
\hline Laws and regulations & 3.43 & 0.65 & Number of tasks & 3.71 & 0.73 \\
\hline Political effects & 4.21 & 0.80 & Dependencies between tasks & 4.50 & 0.52 \\
\hline Project team size & 4.21 & 0.70 & Tasks diversity & 3.86 & 0.77 \\
\hline Trust in project team & 3.36 & 0.74 & Clarity of work structure & 3.64 & 0.63 \\
\hline Team interrelations & 4.64 & 0.63 & Uncertainties in scope & 4.14 & 0.53 \\
\hline Number of different languages & 2.43 & 0.65 & Number of stakeholders & 4.21 & 0.70 \\
\hline Number of different nationalities & 2.57 & 0.85 & Stakeholders locations & 3.43 & 0.65 \\
\hline Contract types & 3.00 & 0.88 & Stakeholders perspectives & 4.36 & 0.63 \\
\hline Experience with parties involved & 3.71 & 0.83 & Stakeholders interrelations & 4.57 & 0.51 \\
\hline Resource and skills availability & 4.71 & 0.47 & Technology diversity & 4.36 & 0.74 \\
\hline Number and variety of resources & 3.00 & 0.68 & Product scope largeness & 3.00 & 0.55 \\
\hline Organizational risk & 2.64 & 0.63 & Technology novelty & 3.86 & 0.66 \\
\hline Interdependence between parties & 4.50 & 0.52 & Interrelations between technological processes & 4.29 & 0.83 \\
\hline Size of budget & 2.71 & 0.99 & Quality requirements & 2.86 & 0.66 \\
\hline Diversity of staff & 4.14 & 0.77 & Technical risk & 3.50 & 0.52 \\
\hline Organizational structure & 3.00 & 0.78 & Number of information systems & 3.79 & 0.70 \\
\hline Project management tools diversity & 3.21 & 0.80 & Variety of information systems & 4.43 & 0.51 \\
\hline Overlapping office hours & 3.29 & 0.73 & Interdependence of information systems & 4.64 & 0.50 \\
\hline Project team configuration & 3.14 & 0.77 & & & \\
\hline
\end{tabular}

\section{Results and discussion}

Based on the results of Table 3, all standard deviations are less than 1 and mean standard deviation of the answers is 0.69 . This means that a reasonable and acceptable consensus has been achieved. Average values for factors are in the range of 2.43 and 4.71 . The Delphi teams decided to consider only the factors whose average values are more than 4 and on this basis, 19 factors were selected and summarized in Table 4 as follows,

\section{Table 4}

The final factors of project complexity

\begin{tabular}{|c|c|c|}
\hline Group & Factors & Average \\
\hline \multirow{3}{*}{ Environmental } & Environmental dependency & 4.29 \\
\hline & Project environment stability & 4.29 \\
\hline & Political effects & 4.21 \\
\hline \multirow{5}{*}{ Organizational } & Project team size & 4.21 \\
\hline & Team interrelations & 4.64 \\
\hline & Resource and skills availability & 4.71 \\
\hline & Interdependence between parties & 4.50 \\
\hline & Diversity of staff & 4.14 \\
\hline \multirow{2}{*}{ Objectives } & Interdependence of objectives & 4.43 \\
\hline & Clarity of objectives & 4.21 \\
\hline \multirow{2}{*}{ Tasks } & Dependencies between tasks & 4.50 \\
\hline & Uncertainties in scope & 4.14 \\
\hline \multirow{3}{*}{ Stakeholders } & Number of stakeholders & 4.21 \\
\hline & Stakeholders perspectives & 4.36 \\
\hline & Stakeholders interrelations & 4.57 \\
\hline \multirow{2}{*}{ Technological } & Technology diversity & 4.36 \\
\hline & Interrelations between technological processes & 4.29 \\
\hline \multirow{2}{*}{ Information systems } & Variety of IS & 4.43 \\
\hline & Interdependence of IS & 4.64 \\
\hline
\end{tabular}

As we can observe, the final factors can be classified into 7 groups, which are: Environmental, organizational, objectives, tasks, stakeholders, technological and information systems. Each of these groups is discussed in the following. There are many industries and professional technology involved 
in construction projects. These technologies are not separated from each other in a project. Therefore, the interaction among professional technologies forms the project technology complexity. There are many stakeholders including owners, designers, contractors, subcontractors, material suppliers, banks, government departments involved in construction projects. These stakeholders have various styles and perspectives, which impose conflicting conditions into the project. In other word, when the perspectives of any stakeholders have a large discrepancy with others perspectives, the stakeholder either adapts or could force others to cope themselves in order to achieve final purpose of project. Construction projects include large number of tasks, which are interrelated in time and space. Each of these tasks comes from various disciplines and has their own characters, structure and function. These tasks are not isolated from each other and influence each other. Note that, one of the obvious characters of these tasks is that they are constantly changing throughout the project.

Projects faced with large amount of information derived from various stakeholders such as owners, designers, contractors, subcontractors, material suppliers, banks, government departments, etc. Thus, access to the required information at the right time and location is more difficult in such circumstances. In addition, since the start of the project, the relevance and interdependence of information systems is also gradually increasing. Every project is performed in order to achieve several goals. Each of these goals satisfies different disciplines from different parts of project. In addition, these goals are not separated and often related and at odds with each other. Construction projects like all types of systems are implemented in their environment surrounding them. The behavior of projects is influenced by various kinds of system environment such as economic environment, social and cultural environment, policy and regulatory environment, and political environment. These environments are constantly changing which lead to increase in complexity. Finally, the business and governance aspects of projects including financial arrangement, scheduling, deployment of resources and decision management cause organizational complexities.

\section{Conclusion}

Construction industry is one of the most important industries in Iran and generates significant income, annually. Despite this, the process of construction is slow, inefficient and costly. One of the critical reasons leading to this is lack of knowledge in modern project management concepts such as complex systems and complexity in projects. In this research, the Delphi method was utilized in order to identify the most important complexity factors in construction industry in Iran. In order to do this, a set of relevant factors were identified through a comprehensive literature review. Next, the Delphi method was used and the most important factors were selected among them. Finally, based on their nature the selected factors were classified into 7 groups. This research can assist Iranian project managers to get familiar and also deal with increasing complexity of construction projects in Iran.

\section{Acknowledgements}

The research is financed by Imam Khomeini International University of Ghazvin. The authors gratefully acknowledge the financial support for this work.

\section{References}

Asnaashari, A., Knight, A., \& Hurst, A. (2009 a). Delays in the Iranian construction projects: Stakeholders and economy. Challenges, Opportunities and Solutions in Structural Engineering and Construction. (Ghafoori ed.). Taylor \& Francis Group, page 699. ISBN 978-0-415-56809-8

Asnaashari, E., Knight, A., Hurst, A., \& Farahani, S.S. (2009 b). Causes of construction delays in Iran: project management, logistics, technology and environment. In: Dainty, A. (Ed) Procs 25th Annual ARCOM Conference, 7-9 September 2009, Nottingham, UK, Association of Researchers in Construction Management, 897-906.

Asnaashari, A., Barangi, B.K, Knight, A., Hurst, A., Rad, A.A., \& Barangi, S.K. (2010). Construction Materials Logistics Management in Building Projects in Iran: The Purchasing Process. The 
Construction, Building and Real Estate Research Conference of the Royal Institution of Chartered Surveyors, Held at Dauphine Université, Paris

Aram, E, \& Noble, D. (1999). Educating prospective managers in the complexity of organizational life. Management Learning, 30(3), 321-42.

Axelrod, R.M, Axelrod, R., \& Cohen, M.D. (2001). Harnessing Complexity: Organizational Implications of a Scientific Frontier. Simon and Schuster, (Chapter 1).

Baccarini, D. (1996). The concept of project complexity- a review. International Journal of Project Management, 14(4), 201-204.

Bertelsen, S. (2004). Construction management in a complexity perspective. 1st International SCRI Symposium, March 30th - 31st 2004 at the University of Salford, UK.

Bosch-Rekveldt, M., Jongkind, Y., Mooi, H., Bakker, H., \& Verbraeck, A. (2011). Grasping project complexity in large engineering projects: The TOE (Technical, Organizational and Environmental) framework. International Journal of Project Management, 29(6), 728-739.

Edmonds, B. (1999). What is complexity? - The philosophy of complexity per se with application to some examples in evolution. In Heylighen, F., \& Aerts, D. (Eds.), the evolution of complexity, Dordrecht: Kluwer.

Geraldi, J.G. (2008). The balance between order and chaos in multi-project firms: A conceptual model. International Journal of Project Management, 26, 348-356.

Hass, K.B. (2009). Managing Complex Projects: A New Model. Management Concepts.

Jolson, M.A., \& Rossow, G.L. (1971). The Delphi process in marketing decision making. Journal of Marketing Research, 8, 443-8.

Latva-Koivisto, A.M. (2001). Finding a complexity measure for business process models. Research report Helsinki University of Technology, Systems Analysis Laboratory.

Maguire, S., \& McKelvey, B. (1999). Complexity and Management: Moving From Fad to Firm Foundations. Emergence, 1(2), 19-61.

McComb, S.A., Green, S.G., \& Compton, W.D., (2007). Team flexibility’s relationship to staffing and performance in complex projects: An empirical analysis. Journal of Engineering and Technology Management, 24, 293-313.

Morel, B., \& Ramanujam, R. (1999). Through the looking glass of complexity: the dynamics of organizations as adaptive and evolving systems. Organization Science, 10 (3), 278-293.

Ogot, M., \& Okudan-Kremer, G. (2004). Engineering Design: A Practical Guide. Trafford Publishing.

Okoli, C., \& Pawlowski, S.D. (2004). The Delphi method as a research tool: an example, design considerations and applications. Information \& Management, 42, 15-29.

Parwani, R.R. (2002). Complexity: an Introduction. University scholars programme, National University of Singapore, Singapore.

Remington, K., \& Pollack, J. (2007). Tools for Complex Projects. Gower Publishing, Ltd

Rowe, G., \& Wright, G. (1999). The Delphi technique as a forecasting tool: issues and analysis. International Journal of Forecasting, 15, 353-375.

Thomas, J., \& Mengel, T. (2008). Preparing project managers to deal with complexity - Advanced project management education. International Journal of Project Management, 26, 304-315.

Uhl-Bien, M., Marion, R., \& McKelvey, B., (2007). Complexity Leadership Theory: Shifting leadership from the industrial age to the knowledge era. The Leadership Quarterly, 18 (4), 298-318

Vidal, L.A., Marle, F., \& Bocquet, J.C. (2011 a). Measuring project complexity using the Analytic Hierarchy Process. International Journal of Project Management, 29(6), 718-727.

Vidal, L.A., Marle, F., \& Bocquet, J.C. (2011 b). Using a Delphi process and the Analytic Hierarchy Process (AHP) to evaluate the complexity of projects. Expert Systems with Applications, 38, 53885405.

Williams, T.M. (1999). The need for new paradigms for complex projects. International Journal of Project Management, 17(5), 269-273.

Williams, T. (2002). Modelling Complex Projects. John Wiley \& Sons.

Whitty, S.J., \& Maylor, H. (2009). And then came Complex Project Management. International Journal of Project Management, 27, 304-310.

Waldrop, M.M. (1999). Complexity: the emerging science at the edge of chaos. Englewood Cliffs, NJ: Simon \& Schuster. 